\title{
Malatya İlinde Çalışan Öğretmenlerin Sağlık Okuryazarlığı Düzeylerinin ve İlişkili Faktörlerin Belirlenmesi
}

\author{
Determination of Health Literacy Levels and Related Factors of Teachers \\ Working in Malatya
}

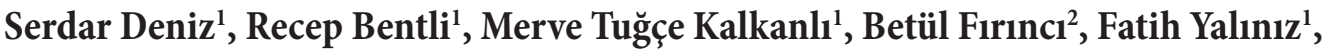 \\ Ekrem Demir ${ }^{3}$, Ayșe Ferdane Oğuzöncïl ${ }^{4}$, Muhsin Akbaba $^{5}$ \\ ${ }^{1}$ Malatya İl Sağlık Müdürlü̈̆̈̈, Malatya, Türkiye \\ ${ }^{2}$ İnönü Üniversitesi Tip Fakültesi, Halk Sağlı̆̆ı Anabilim Dalı, Malatya, Türkiye \\ ${ }^{3}$ Malatya Milli Eğitim Müdürlüğü, Malatya, Türkiye \\ ${ }^{4}$ Fırat Üniversitesi Tip Fakültesi, Halk Sağlığı Anabilim Dalı, Elazı̆̆, Türkiye \\ ${ }^{5}$ Çukurova Üniversitesi Tip Fakültesi, Halk Sağlığı Anabilim Dalı, Adana, Türkiye
}

\author{
Yazıșma Adresi / Correspondence: \\ Serdar Deniz \\ Malatya İl Sağlık Müdürlüğü, İzzetiye Mh. İnönü Cd. No:5/1 Battalgazi / MALATYA \\ T: +90507233 3473 E-mail: : dr.serdardeniz@gmail.com \\ Geliş Tarihi / Received : 22.10.2019 Kabul Tarihi / Accepted : 02.01.2020
}

Orcid :

Serdar Deniz https://orcid.org/0000-0002-6941-4813

Recep Bentli https://orcid.org/0000-0002-7205-0379

Merve Tuğçe Kalkanlı https://orcid.org/0000-0002-5328-2668

Betuil Firınci https://orcid.org/0000-0001-5685-4142
Fatih Yalınız https://orcid.org/0000-0002-9194-7683

Ekrem Demir https://orcid.org/0000-0002-4936-0790 Ayșe Ferdane Oğuzöncül https://orcid.org/0000-0002-9820-9720

Muhsin Akbaba https://orcid.org/0000-0003-3028-6698

(Sakarya Tip Dergisi / Sakarya Med J 2020, 10(1):28-36) Doi: 10.31832/smj.636313

Çalıșma (özet olarak) 26-30 Kasım 2019 tarihleri arasında Antalya'da düzenlenmiş olan 3. Uluslararası 21. Ulusal Halk Sağlığı Kongresinde sözlü bildiri olarak sunulmuştur

$\ddot{O} z$

Amaç Sağlık okuryazarlığı (SOY) sağlı̆̆a ilişkin bilgilere erişim, bu bilgilerin anlaşılması ve uygulanması süreçlerini kapsayan bilișsel ve sosyal bir beceridir. Öğretmenlerin SOY düzeyleri, çalıştıkları ve içinde bulundukları sosyal ortam nedeni ile hem kendileri hem toplum açısından oldukça önemlidir. Kesitsel nitelikteki bu araștırmada Malatya ilinde çalıșan öğretmenlerin SOY düzeyinin ve ilișkili faktörlerin belirlenmesi amaçlanmıștır.

Gereç ve Bu çalıșma, Malatya İl Milli Eğitim Müdürlüğüne bağlı okullarda çalıșan öğretmenlere uygulandı. Malatya’da Milli Eğitim Müdürlüğüne bağlı okullarda çalışan toplam öğretmen sayısı 11.851'di. Toplam 1000 kişiye ulaşılması hedeflenen araştırmada 875 katılımcının cevapları değerlendirildi. Anket formu 4 bölümden oluşmaktaydı. Birinci bölümünde; 16 sorudan oluşan sosyo - demografik sorular bulunmaktaydı. İkinci ( 47 soru), üçüncü (12 soru) ve dördüncü (11 soru) bölümlerinde veri toplama aracı olarak Sağlık-Sen Türkiye Sağlık Okuryazarlı̆̆ı Araştırması için Türkçe'ye çevrilen Avrupa Sağlık Okuryazarlı̆̆ı Araştırması Anketi (HLS-EU-Q) kullanıldı.

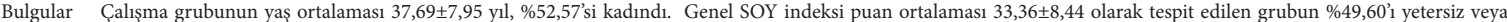
sorunlu SOY kategorisinde yer almaktaydı. Eğitim, ekonomik durum ve genel sağlık durumuna göre SOY düzeylerinin farklı olduğu tespit edildi (p<0,05).

Sonuç Toplumun yüksek eğitim seviyesine sahip bireylerinden olan öğretmenlerin, yaklașık yarısının yetersiz veya sorunlu SOY düzeyinde olduğu görülmektedir. Öğretmenlerin SOY düzeylerinin tespiti çalışmalarının artırılması ve bu tespitler neticesinde gerekli müdahalelerin yapılması gerekmektedir.

Anahtar Öğretmen; sağlığı geliștirme; sağlık okuryazarlı̆̆

Kelimeler

Abstract

Objective Health literacy (HL) is a cognitive and social skill that covers the processes of accessing, understanding and applying information about health. The teachers' HL levels are very important both for themselves and the society because ofthe social environment in which they work and live.In this cross-sectional study, it was aimed to determine the HL level and related factors of teachers working in Malatya

Materials This study was applied to teachers working in Malatya Provincial Directorate of National Education. The total number of teachers were 11.851. In the study, which aims to reach 1000 people, and Methods the responses of 875 participants were evaluated. The questionnaire consisted of 4 sections. In the first part: There were socio-demographic questions consisting of 16 questions. Second (47questions), third (12questions) and fourth (11questions) as a data collection tool, Saglik-Sen Turkey Health Literacy Survey were used.

Results The mean age of the study group was $37.69 \pm 7.95$ year and $52.57 \%$ were female. The mean score of general $H L$ index was found to be $33.36 \pm 8.44$, and $49.60 \%$ of the group was in the inadequate or problematic HL category.HL levels were found to be different according to education, economic status and general health status $(p<0.05)$.

Conclusion It is seen that approximately half of the teachers who are at the top of the society in terms of education level are inadequate or problematic HL level. It is necessary to increase the efforts to determine the HL levels of teachers and to make the necessary interventions as a result of these findings.

Keywords Teacher; health promotion; health literacy 


\section{Giriş}

Sağlık okuryazarlığı (SOY), 2012'de Dünya Sağlık Örgütü (DSÖ)'ne üye devletler tarafından benimsenen, sağlıkla ilgili kararlara katılım ve sağlı̆̆ın geliştirilmesini sağlayan eylemlerin hem aracı hem sonucu rolündedir. ${ }^{1,2}$

SOY kapsamlı bir tanımda; hayat boyu yaşam kalitesini korumak ve iyileştirmek amacıyla hastalıklardan korunma, sağlık hizmetleri ve sağlı̆̆ın geliştirilmesi ile ilgili kararlar alabilmek için sağlıkla ilgili bilgilere erişim, bu bilgileri anlama, değerlendirme ve uygulamaya yönelik bilgi, motivasyon ve yetenek olarak tanımlanmıştır. SOY düzeyinin yetersiz olması kronik hastalıkların kontrolü ve tedavisinin önünde büyük bir engel olarak durmaktadır. ${ }^{3-5}$ Sağlığı koruma ve geliştirmeye yarayan bilgilere erişim, bu bilgileri anlama ve uygulama becerisi olan SOY, toplumun sağlık hizmetlerine katılımını güçlendirmekle birlikte, sağlık hizmetlerinin maliyetini azaltıp, etkinliğini arttırmak için mutlaka önem verilmesi gereken bir konudur. Sağlığa ilişkin uygulamaların ve bunun için gereken okuma ve sayısal işlemlerin doğru bir şekilde yapılıyor olması, SOY göstergesidir. Bu bilişsel ve sosyal becerinin, broşür okuma veya randevu almadan daha kapsamlı olarak yaşama yansıması beklenmektedir. ${ }^{6-9}$

SOY düzeyini etkileyen faktörler oldukça geniş bir skalada bulunsa da yapılan araştırmalarda; yaş, cinsiyet, eğitim düzeyi gibi faktörlerin ön plana çıktığı görülmektedir. ${ }^{10-14}$ SOY düzeyinin belirlenmesi; hastaların ihtiyaçlarına göre sağlık hizmetlerinin planlanması ve personel yetiştirilmesi, sağlıkla ilgili kararlara toplum katılımının sağlanması ve bölgeler arası farklılıkları tespit ederek uygun eylem planları oluşturulması açısından gereklidir. ${ }^{15}$

Avrupa Sağlık Okuryazarlığı araştırmasında 8 katılımcı ülkede yetersiz veya sorunlu SOY sıklığının \%47,6 olduğu, eğitim seviyesi yüksek olan bireylerin SOY düzeyinin yüksek olduğu belirlenmiştir. Bununla birlikte finansal yoksulluk, düşük sosyal statü ve yaşlılığın SOY seviyesi üzerinde olumsuz etki gösterdiği tespit edilmiştir. ${ }^{16}$ Tür- kiye Sağlık Okuryazarlığı araştırmasında yetersiz veya sorunlu SOY sıklığı \%64,6 olarak belirlenmiştir. ${ }^{13}$ Bilişsel işlevselliğin azalması ve hastalık durumlarının artmasına bağlı olarak yaşlılık döneminde SOY seviyesinin azaldığ bilinmektedir. ${ }^{17}$ SOY düzeyinin düşük olması; riskli davranışlar, düşük sağlık düzeyi, tedaviye uyum sağlama sorunları, hastanede kalış sürelerinin artması ve yüksek sağlık harcamaları ile ilişkilidir. Sonuç olarak hem insan kaynağ hem de finansal kaynaklar üzerinde olumsuz etkide bulunmaktadır. ${ }^{16,18}$

Öğretmenlerin SOY düzeyleri, çalıştıkları ve içinde bulundukları sosyal ortam nedeni ile hem kendileri hem toplum açısından oldukça önemlidir. Kesitsel nitelikteki bu araştırmada Malatya ilinde çalışan öğretmenlerin SOY düzeyinin ve ilişkili faktörlerin belirlenmesi amaçlanmıştır.

\section{Gereç ve Yöntem}

Kesitsel nitelikteki bu çalışma, Malatya İl Milli Eğitim Müdürlüğ̈̈’ne bağlı okullarda çalışan öğretmenlere uyguland. Araştırmanın, saha çalışmaları 10 Eylül-1 Aralık 2018 tarihleri arasında tamamland.

Malatya’da Milli Eğitim Müdürlügüne bağlı okullarda çalışan toplam öğretmen sayısı 11.851'di. Yeterli veya mükemmel SOY sıklığ $\% 35,4$, hata pay1 \%5, güven aralığg $\% 95$ olarak hesaplama yapıldı ve minimum örneklem büyüklüğü 341 hesapland. ${ }^{13}$ Araştırma grubunun her iki cinsiyeti temsil etmesi amaciyla (341x2) 682 olarak belirlenen örneklem büyüklügü; ölçek puanlarının hesaplanabileceği yeterlilikte soruya yanıt vermeme, araştırmayı kabul etmeme, anket uygulaması esnasında görev yerinde bulunmama gibi nedenler göz önünde bulundurularak 1000 kişi olarak hedeflendi. Öğretmenler isim-soyisim sırasına gore sıralandıktan sonra 1 ile 12 arasında bir sayı belirlendi. $\mathrm{Bu}$ sayıya 11 eklenerek belirlenen her sayıya denk gelen öğretmen örnekleme alındı. Çalışma sonunda 875 kişiye ulaşıldı.

Literatür taranarak araştırmacılar tarafından hazırlanmış 
olan anket formu 4 bölümden oluşmaktaydı. Anketin birinci bölümünde; 16 sorudan oluşan sosyo - demografik sorular, ikinci bölümünde; 47 soruluk SOY ölçeği, üçüncü bölümünde 12 soruluk sağlık durumu, hastalıklar, sağlık hizmetinin kullanımı ve yaşam koşulları ile ilgili sorular, dördüncü bölümünde; 11 sorudan oluşan acil sağlık hizmetlerini, sağlık hizmetlerini ve koruyucu sağlık hizmetlerini kullanım durumunu sorgulayan sorular bulunmaktaydı. Anketin ikinci, üçüncü ve dördüncü bölümlerinde veri toplama aracı olarak Sağlık ve Sosyal Hizmet Çalışanları Sendikası tarafından Türkiye’ye ve Türkçe’ye uyumlu hale getirilerek geçerlik ve güvenirlik çalışması yapılmış olan Sağlık Okuryazarlığı Anketi kullanıldı. ${ }^{13}$

SOY ölçeğinin puanlanması: Toplam 50 puan üzerinden değerlendirilen 47 soruluk Sağlık Okuryazarlığı Anketi Avrupa Birliği ölçeğine göre; aldıkları puanlara bakılarak yetersiz, sorunlu, yeterli ve mükemmel SOY olmak üzere 4 gruba ayrıld 1 (0-25 = yetersiz, $>25-33=$ sorunlu, $>33-42=$ yeterli, $>42-50=$ mükemmel).

İnönü Üniversitesi Sağlık Bilimleri Girişimsel Olmayan Klinik Araştırmalar Etik Kurulundan 04.09.2018 tarihinde 2018/16-33 karar sayısı ile onay alındı. Araştırmanın; bilgilendirilmiş gönüllü onamını da içeren anket formları katılımcılara gözlem altında uygulandı. Elde edilen verilerin analizi için SPSS 25 paket program kullanıldı. Araştırmada anlamlılık düzeyi $\mathrm{p}<0,05$ olarak belirlendi. Veriler sayı, yüzde, ortalama ve standart sapmalar ile sunuldu. Kategorik verilerin karşılaştırılmasında Ki-kare testi kullanıldı.

\section{Bulgular}

Çalışma grubunun \%52,57'si் ( $\mathrm{n}=460)$ kadın, yaş ortalamas1 37,69 $\pm 7,95$ yıl (min. 23, maks. 66), aylık hane geliri ortalaması $5.613 \pm 1.825 \mathrm{TL}$ (min. 3.000, maks. 15.000) olarak tespit edildi. Çocuk sahibi olmayanlar grubun \%25,37’sini ( $\mathrm{n}=222)$ oluşturmaktaydı. Katılımcıların tamamının sağlık güvencesi bulunmaktaydı. Grubun sosyodemografik ve sosyoekonomik değişkenlerinin dağılımı Tablo 1'de sunulmuştur.

Çalışma grubunun \%36,11'inin $(\mathrm{n}=316)$ fazla kilolu, \%8,34'ünün ise obez olduğu tespit edildi. Grubun tamamı acil sağlık hizmetlerinin telefon numarasını (112) bilmekteydi. \%27,20'si $(n=238)$ daha önce ambulans çağırmıştı. 6 ay ve daha uzun süren hastalığı bulunmayanlar grubun \%64,34'ünü ( $n=563)$ oluşturmaktaydı. Çalışma grubunun sağlık, hastalık, zararlı alışkanlık ve hekim seçme hakkını kullanma durumu Tablo 2'de sunulmuştur.

Katılımcıların genel SOY indeksi puan ortalaması 33,36 $\pm 8,44$ (min. 4,61, maks. 50,00) olarak tespit edildi. Grubun $\% 49,60{ }^{\prime} 1(n=434)$ yetersiz veya sorunlu, $\% 50,40$ '̈u

\begin{tabular}{|c|c|c|c|}
\hline & & $\mathrm{n}$ & $\%$ \\
\hline \multirow{2}{*}{ Cinsiyet } & Kadın & 460 & 52,57 \\
\hline & Erkek & 415 & 47,43 \\
\hline \multirow{3}{*}{ Medeni durum } & Evli & 715 & 81,71 \\
\hline & Bekar & 135 & 15,43 \\
\hline & Ayrılmış/ Dul & 25 & 2,86 \\
\hline \multirow{2}{*}{ Eğitim durumu } & Ön lisans/ Lisans & 750 & 85,71 \\
\hline & Yüksek lisans/ Doktora & 125 & 14,29 \\
\hline \multirow{3}{*}{$\begin{array}{l}\text { Ekonomik durum } \\
\text { değerlendirme }\end{array}$} & Kötü & 72 & 8,23 \\
\hline & Orta & 631 & 72,11 \\
\hline & İyi & 172 & 19,66 \\
\hline \multirow{3}{*}{ Sağlık masraflarını karşılama } & Çok kolay & 436 & 49,83 \\
\hline & Kismen & 418 & 47,77 \\
\hline & Çok zor & 21 & 2,40 \\
\hline
\end{tabular}


Sakarya Tip Dergisi 2020;10(1):28-36

DENiZ ve Ark., Öğretmenlerde Sağlık Okuryazarlığı Düzeyi

\begin{tabular}{|c|c|c|c|}
\hline Soru & Cevap & $\mathrm{n}$ & $\%$ \\
\hline \multirow{5}{*}{ Genel olarak sağlık durumunuz nasıldır? } & Çok iyi & 74 & 8,46 \\
\hline & İyi & 502 & 57,37 \\
\hline & Orta & 257 & 29,37 \\
\hline & Kötü & 34 & 3,89 \\
\hline & Çok kötü & 8 & 0,91 \\
\hline \multirow{3}{*}{ Uzun süreli / kronik hastalığınız var mı? } & Evet birden fazla & 88 & 10,06 \\
\hline & Evet 1 & 224 & 25,60 \\
\hline & Hayır & 563 & 64,34 \\
\hline \multirow{3}{*}{ Sigara/diğer tütün ürünleri kullanır mısınız? } & Kullaniyor & 187 & 21,37 \\
\hline & $\begin{array}{l}\text { Daha önce } \\
\text { kullanıp bırakmıș }\end{array}$ & 104 & 11,89 \\
\hline & $\begin{array}{l}\text { Hiç } \\
\text { kullanmamış }\end{array}$ & 584 & 66,74 \\
\hline \multirow{2}{*}{ Son 1 yılda alkol kullandınız mı? } & Evet & 352 & 40,23 \\
\hline & Hayır & 523 & 59,77 \\
\hline \multirow{2}{*}{ Hekim seçme hakkınız olduğunu biliyor musunuz? } & Evet & 809 & 92,46 \\
\hline & Hayır & 66 & 7,54 \\
\hline
\end{tabular}

( $\mathrm{n}=441)$ yeterli veya mükemmel SOY kategorisindeydi.

SOY ölçeğinde bulunan tüm sorularda, minimum puanın 1, maksimum puanın 4 olduğu görüldü. En düşük puan ortalamasına sahip olan madde Sağlık hizmetlerinde bilgiyi değerlendirme kategorisindeki S1.12 (Medyada hastalık hakkındaki bilginin güvenilirliğini değerlendirmek =
$2,78 \pm 0,83)$, en yüksek puan ortalamasına sahip olan madde Sağlık hizmetlerinde bilgiyi uygulama kategorisindeki S1.15 (Acil durumda ambulans çağırmak $=3,20 \pm 0,64$ ) olarak tespit edildi. Medeni durum $(\mathrm{p}=0,131)$ ve çocuk sahibi olma durumunun ( $\mathrm{p}=0,890)$ SOY kategorisini etkilemediği tespit edildi. Eğitim durumu ve ekonomik durum SOY kategorileri üzerinde etkili olmaktaydı $(\mathrm{p}<0,05)$ (Tablo 3$)$. 
Sakarya Tip Dergisi 2020;10(1):28-36

DENIZ ve Ark., Öğretmenlerde Sağlık Okuryazarlığı Düzeyi

\begin{tabular}{|c|c|c|c|c|c|c|c|}
\hline & & \multicolumn{4}{|c|}{ SOY Kategorisi } & \multirow[b]{3}{*}{$\mathrm{X} 2$} & \multirow[b]{3}{*}{$\mathrm{p}$} \\
\hline & & \multicolumn{2}{|c|}{ Yetersiz veya sorunlu } & \multicolumn{2}{|c|}{ Yeterli veya mükemmel } & & \\
\hline & & $\mathrm{n}$ & $\%$ & $\mathrm{n}$ & $\%$ & & \\
\hline \multirow{2}{*}{ Cinsiyet } & Kadın & 235 & 51,09 & 225 & 48,91 & \multirow{2}{*}{0,858} & \multirow{2}{*}{0,354} \\
\hline & Erkek & 199 & 47,95 & 216 & 52,05 & & \\
\hline \multirow{2}{*}{ Yaş grubu } & $23-40$ & 296 & 49,42 & 303 & 50,58 & \multirow{2}{*}{0,026} & \multirow{2}{*}{0,872} \\
\hline & $\geq 41$ & 138 & 50,00 & 138 & 50,00 & & \\
\hline \multirow{2}{*}{ Eğitim } & Ön lisans/Lisans & 356 & 47,47 & 394 & 52,53 & \multirow{2}{*}{9,558} & \multirow{2}{*}{0,002} \\
\hline & Yüksek lisans/Doktora & 78 & 62,40 & 47 & 37,60 & & \\
\hline \multirow{3}{*}{ Aylik hane geliri } & $3000-5000$ & 227 & 52,67 & 204 & 47,33 & \multirow{3}{*}{8,817} & \multirow{3}{*}{0,012} \\
\hline & $5001-7000$ & 152 & 50,50 & 149 & 49,50 & & \\
\hline & $\geq 7001$ & 55 & 38,46 & 88 & 61,54 & & \\
\hline \multirow{3}{*}{$\begin{array}{l}\text { Ekonomik } \\
\text { durum }\end{array}$} & Kötü & 42 & 58,33 & 30 & 41,67 & \multirow{3}{*}{15,403} & \multirow{3}{*}{$<0,001$} \\
\hline & Orta & 329 & 52,14 & 302 & 47,86 & & \\
\hline & İyi & 63 & 36,63 & 109 & 63,37 & & \\
\hline \multirow{3}{*}{$\begin{array}{l}\text { Sağlık } \\
\text { masraflarını } \\
\text { karşılama }\end{array}$} & Çok kolay & 182 & 41,74 & 254 & 58,26 & \multirow{3}{*}{21,460} & \multirow{3}{*}{$<0,001$} \\
\hline & Kismen & 240 & 57,42 & 178 & 42,58 & & \\
\hline & Çok zor & 12 & 57,14 & 9 & 42,86 & & \\
\hline \multirow{3}{*}{$\begin{array}{l}\text { Genel olarak } \\
\text { sağlığınız nasıl? }\end{array}$} & Çok iyi/İyi & 245 & 42,53 & 331 & 57,47 & \multirow{3}{*}{34,325} & \multirow{3}{*}{$<0,001$} \\
\hline & Orta & 160 & 62,26 & 97 & 37,74 & & \\
\hline & Çok kötü/kötü & 29 & 69,05 & 13 & 30,95 & & \\
\hline \multirow{2}{*}{$\begin{array}{l}\text { Uzun süreli } \\
\text { hastalık sayısı }\end{array}$} & Yok & 267 & 47,42 & 296 & 52,58 & & \\
\hline & $\geq 1$ & 167 & 53,53 & 145 & 46,47 & 2,989 & 0,084 \\
\hline & 0 & 84 & 60,00 & 56 & 40,00 & & \\
\hline Son 1 yılda sağlık & $1-2$ & 73 & 41,71 & 102 & 58,29 & 10592 & \\
\hline $\begin{array}{l}\text { kuruluşlarına } \\
\text { başvuru sayısı }\end{array}$ & $3-5$ & 140 & 50,36 & 138 & 49,64 & 10,592 & 0,014 \\
\hline & $\geq 6$ & 137 & 48,58 & 145 & 51,42 & & \\
\hline & Kullaniyor & 95 & 50,80 & 92 & 49,20 & & \\
\hline $\begin{array}{l}\text { Sigara kullanma } \\
\text { durumu }\end{array}$ & Birakmış & 54 & 51,92 & 50 & 48,08 & 0,482 & 0,786 \\
\hline & Kullanmiyor & 285 & 48,80 & 299 & 51,20 & & \\
\hline Son 1 yilda & Evet & 173 & 49,15 & 179 & 50,85 & & \\
\hline $\begin{array}{l}\text { alkol kullanma } \\
\text { durumu }\end{array}$ & Hayır & 261 & 49,90 & 262 & 50,10 & 0,048 & 0,826 \\
\hline Hekiminizi & Evet & 393 & 48,58 & 416 & 51,42 & & \\
\hline $\begin{array}{l}\text { olduğunu biliyor } \\
\text { musunuz? }\end{array}$ & Hayır & 41 & 62,12 & 25 & 37,88 & 4,477 & 0,034 \\
\hline & Zayıf veya Normal & 242 & 49,79 & 244 & 50,21 & & \\
\hline BKİ Kategorisi & Fazla kilolu & 157 & 49,68 & 159 & 50,32 & 0,088 & 0,957 \\
\hline & Obez & 35 & 47,95 & 38 & 52,05 & & \\
\hline
\end{tabular}




\section{Tartışma}

SOY seviyesinin ortaya konması giderek önem kazanmakla birlikte, meslek gruplarına yönelik araştırmalar içerisinde öğretmenlerde yapılan yeterli sayıda çalışmanın olmadığı anlaşılmaktadır.

Çalışmamızda öğretmenlerin \%49,60’nın yetersiz veya sorunlu SOY düzeyinde olduğu, yeterli veya mükemmel SOY düzeyinde olanlar ile benzer sıklıkta bulunduğu tespit edildi. Grubun genel SOY indeksi puan ortalama-

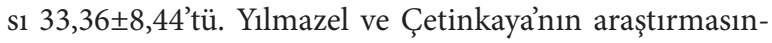
da, öğretmenlerin \%73,8'inin çok sınırlı veya sınırlı SOY, \%26,2'sinin yeterli SOY düzeyinde olduğu belirlenmiştir. ${ }^{19}$ Avrupa Sağlık Okuryazarlığı araştırmasında puan ortalaması 33,8 $\pm 8,0$ yetersiz veya sorunlu SOY sıklığı \%47,6 Türkiye Sağlık Okuryazarlığı araştırmasında ise puan ortalaması 30,4 yetersiz veya sorunlu SOY sıklığ1 \%64,6 olarak tespit edilmiştir. ${ }^{13,16}$

Araştırmamızda erkeklerde yeterli veya mükemmel SOY sıklığı kadınlara göre daha yüksek olsa da bu farkın anlamlı olmadığı tespit edildi. Benzer şekilde Mısır'da hastaneye başvuran hasta ve hasta yakınları ile yapılan bir çalışmada, kadınların sadece \%10,2'sinin, erkeklerin \%19,6’sının yeterli SOY düzeyine sahip olduğu tespit edilmiştir. ${ }^{20}$ Özdemir ve arkadaşlarının araştırmasında erkek hastaların SOY düzeyi kadınlardan yüksek bulunmuştur. ${ }^{21}$ İngiltere’de yapılan bir araştırmada yeterli SOY sıklığı kadınlarda daha yüksek bulunmuştur. ${ }^{22}$ Tayvan'da bir hastanede yapılan çalışmada erkek cinsiyet ve SOY arasında negatif yönde anlamlı ilişki olduğu saptanmıştır. ${ }^{23}$ Sağlık kurumlarına başvuran hastalarda yapılan bir araştırmada kadın hastalarda SOY ile ilgili aktivitelere yönelik puanların daha yüksek olduğu belirlenmiştir. ${ }^{14}$

Yapılan çalışmalar cinsiyetin SOY düzeyini etkilediğini gösterse de yaş, eğitim, sosyo-ekonomik durum, sağlık durumu gibi değişkenlerle birlikte değerlendirilmesi gerektiğini göz ardı etmemek gerekmektedir. Çalışmamızda öğretmenlerin sosyodemografik özelliklerinin benzerlik göstermesi cinsiyete göre anlamlı farklılık oluşmamasında etkili olabilir.

Çalışmamızda yeterli veya mükemmel SOY sıklı̆̆ $23-40$ yaş grubunda $\% 50,58,41$ ve üzeri yaş grubunda ise $\% 50,00$ olarak tespit edildi. ABD'de yapılan Ulusal Yetişkin Okuryazarlığının Değerlendirilmesi çalışmasında; 65 yaş ve üzeri gruptaki bireylerin gençlere göre daha düşük SOY düzeyine sahip olduğu gösterilmiştir. ${ }^{24}$ İngiltere’de yapılan araştırmada 18-44 yaş grubundaki katılımcıların \%5,7'sinin, 65 yaş ve üzeri gruptakilerin ise \%30'unun sınırda veya yetersiz işlevsel SOY düzeyinde olduğu görülmüştür. ${ }^{22}$ Avrupa Sağlık Okuryazarlığı araştırmasında, SOY düzeyi konusunda yaşın güçlü bir belirleyici olduğu ve yaş arttıkça SOY düzeyinin düşme eğiliminde olduğu belirlenmiştir. ${ }^{25}$ Mısır'da hastaneye başvuran hasta ve hasta yakınlarında yapılan araştırmada, 20-39 yaş grubunda \%19 olan yeterli SOY sıklığının, 40-59 yaş grubunda \% 11,7 olduğu tespit edilmiştir. ${ }^{20}$

Literatürde ileri yaş grubunun genç yaş grubuna göre daha düşük SOY düzeyine sahip olduğunu gösteren çok sayıda çalışma vardır. Çalışmamızda yaş ile SOY düzeyi arasında herhangi bir ilişki tespit edilememiştir. Bu sonucun ortaya çıkmasında, çalışma grubumuzda en yüksek yaşın 66 olması ve grubun büyük bir kısmının 65 yaşından küçük olması etkili olabilir.

Çalışma grubumuzda ön lisans/lisans mezunlarının, yüksek lisans/doktora eğitimi almış olanlara göre yeterli veya mükemmel SOY sıklığı daha yüksek bulundu. Öğretmenlerde yapılan bir araştırmada çalışmamızın aksine eğitim düzeyi yüksek olan öğretmenlerin SOY düzeyleri daha yüksek bulunmuştur. ${ }^{19}$ Avrupa Sağlık Okuryazarlığ 1 araştırmasında eğitim düzeyi yükseldikçe SOY düzeyinin de yükseldiği tespit edilmiştir. ${ }^{25}$ İngiltere'de yapılan bir çalışmada yeterli SOY düzeyi üniversite mezunu olanlarda daha yüksek bulunmuştur. ${ }^{22}$ Benzer şekilde Türkiye Sağlık Okuryazarlığı araştırmasında eğitim düzeyi ile SOY arasında pozitif yönde bir ilişki olduğu tespit edilmiştir. ${ }^{13}$ 
Literatür incelendiğinde eğitim düzeyi ve SOY ilişkisinin çalışmamızdan farklı olduğu, yüksek eğitim seviyelerinde daha yüksek SOY düzeyleri bulunduğu anlaşılmaktadır.

Çalışmamızda aylık hane geliri 7001 TL ve üzeri olanlar, ekonomik durumunu iyi olarak ifade edenler ve sağlık masraflarını çok kolay karşıladığını belirtenlerde yeterli veya mükemmel SOY sıklığı diğer gruplara göre daha yüksek bulundu. ABD'de 2003 yılında yapılmış olan çalışmada finansal durumu yoksulluk seviyesinin altında olanların SOY düzeyi en düşük olan grup olduğu, gelir arttıkça SOY düzeyinin de yükseldiği belirlenmiştir. ${ }^{24}$ İngiltere'de yapılan bir çalışmada yeterli SOY sıklığının yıllık 20.000 avro ve üzeri gelire sahip olanlarda daha yüksek olduğu görülmüştür. ${ }^{22}$ Avrupa Sağlık Okuryazarlığı araştırmasında düşük SOY seviyesi, düşük sosyo-ekonomik durum ile ilişkilendirilmiştir. ${ }^{25}$ Hastalarda uygulanan bir SOY araştırmasında, geliri giderinden az olanların diğer gruptakilere göre SOY puan ortalamalarının daha düşük olduğu belirlenmiştir. ${ }^{14}$

Literatürdeki araştırmalar çalışmamıza benzer şekilde ekonomik durum ile SOY düzeyinin ilişkili olduğunu göstermektedir.

Çalışmamızda, genel olarak sağlığını çok iyi/iyi şeklinde değerlendirenlerin çoğunun yeterli veya mükemmel SOY düzeyinde olduğu, çok kötü/kötü şeklinde değerlendirenlerin ise büyük bir kısmının yetersiz veya sorunlu SOY seviyesine sahip olduğu görüldü. Çalışmamızda olduğu gibi fiziksel ve/veya psikolojik olarak iyi hisseden yetişkinlerde, SOY seviyesinin daha yüksek olduğu çalışmalar mevcuttur. ${ }^{26,27}$ Öğretmenlerde yapılan bir araştırmada genel sağlık durumunun SOY düzeyini etkilemediği tespit edilmiştir. ${ }^{19}$ Uğurlu ve Akgün'ün çalışmasında da benzer şekilde, sağlık durumlarını kötü/çok kötü olarak değerlendirenlerin diğer gruplara göre daha düşük SOY puanları aldığı tespit edilmiştir. ${ }^{14}$

Araştırma grubumuzda, uzun süreli hastalığı olmayanlar- da yeterli veya mükemmel SOY sıklığı daha fazla olsa da bu ilişki istatistiksel olarak anlamlı değildi. Öğretmenlerde yapılan bir araştırmada kronik hastalığ 1 olmayanlarda yeterli SOY sıklığı daha yüksek bulunmuş ancak bu farkın çalışmamıza benzer şekilde, anlamlı olmadığg tespit edilmiştir. ${ }^{19}$ SOY ve iletişimin diyabet yönetimine etkisinin incelendiği bir çalışmada, hastalıkla ilgili tecrübelerin, hastalık süresinin uzamasının, tedavideki karmaşıklığın ve birlikte farklı hastalıkların görülmesinin SOY düzeyi ile ilişkili olduğu gösterilmiştir. ${ }^{28}$

Son bir yılda sağlık kuruluşlarına başvuru sayısına göre yapılan değerlendirmede yeterli veya mükemmel SOY sıklığı, en yüksek son 1 yılda 1-2 kez, en düşük hiç başvurmayan grupta tespit edildi. Çin'de yaşlılar ile yapılan çalışmada, yıllık muayene olanlarda SOY düzeyinin daha yüksek olduğu belirlenmiştir. ${ }^{27}$ Bir başka araştırmada yetersiz SOY düzeyine sahip olanların daha sık doktor ziyaretinde bulunduğu tespit edilmiş ve bu sonuç yetersiz hissetme ve dış kontrol odaklı olmaya bağlanmıştır. ${ }^{29}$

Sigara kullanma ve son bir yılda alkol kullanma durumu çalışmamızda SOY düzeyini etkilememekteydi. Benzer şekilde Yılmazel ve Çetinkayảnın, öğretmenlerle yaptığı çalışma sonucunda sigara ve alkol kullanımına göre SOY düzeyi arasında fark bulunmamıştır. ${ }^{19}$ Dolye ve arkadaşları tarafından yapılan araştırmada sigara kullanımı ve SOY arasında negatif korelasyon bulunurken, alkol kullanımı ile herhangi bir ilişki tespit edilmemiştir. ${ }^{30}$ Bununla birlikte alkol ve sigara kullanımının, düşük SOY düzeyi ile ilişkilendirildiği çalışmalar da bulunmaktadır. ${ }^{26,27,31-33}$

Çalışmamızda katılımcıların \% 92,46'sı hekim seçme hakkının olduğunu, tamamı acil sağlık hizmetlerinin telefon numarasını (112) bilmekteydi. Hekim seçme hakkı olduğunu bilenler ile bilmeyenler arasında SOY düzeyi açısından anlamlı fark bulunmaktaydı. Hekim seçme hakkı olduğunu bilmeyenlerde yetersiz veya sorunlu SOY sıklığı oldukça yüksekti. Özaydın ve arkadaşları tarafından yapılan araştırmada, katılımcıların \% 75,1'inin hekim seçme 
hakkı olduğunu bildiği ve bu bilginin SOY düzeyi ile ilişkili bulunmadı̆̆ı gösterilmiştir. ${ }^{34}$

Çalışmamızda katılımcıların \% 8,34'ü obezdi. Beden kitle indeksi ile SOY düzeyi arasında anlamlı ilişki bulunmamaktaydı. Bulgularımıza benzer şekilde Shah ve arkadaşları ile Liu ve arkadaşları tarafından yapılan araştırmalarda beden kitle indeksine göre SOY seviyelerinde farklılık olmadı̆̆ 1 tespit edilmiştir. ${ }^{27,32}$ Sağlıkla ilgili yaşam kalitesi ve SOY düzeyinin karşılaştırıldı̆̆ farklı bir çalışmada ise kilolu olma ile SOY arasında ilişki bulunmuş, düşük SOY düzeyine sahip kişilerin daha kilolu oldukları tespit edilmiştir. ${ }^{33}$

Sonuç olarak, toplumun yüksek eğitim seviyesine sahip bireylerinden olan öğretmenlerde SOY düzeyinin yeterli olmadığı, yaklaşık yarısının yetersiz veya sorunlu SOY düzeyinde olduğu görülmektedir. Akademisyenlerin, yöneticilerin ve politika yapıcıların kolay ulaşabileceği birimlerde görev yapan öğretmenlerin, SOY düzeylerinin tespiti çalışmalarının artırılması gerekmektedir. Bu tespitler neticesinde gerekli eylem planları hazırlanarak uygulamaya konulmalıdır. 
Sakarya Tip Dergisi 2020;10(1):28-36

DENIZ ve Ark., Öğretmenlerde Sağlık Okuryazarlığı Düzeyi

\section{Kaynaklar}

1. Kickbusch I, Pelikan JM, Apfel F, Tsouros AD, editors. Health literacy: the solid facts. Copenhagen: World Health Organization Regional Office for Europe; 2013. 73 p.

2. Pleasant A, Kuruvilla S. A tale of two health literacies: public health and clinical approaches to health literacy. Health Promotion International 2008;23(2):152-9.

3. Sørensen K, Van den Broucke S, Fullam J, Doyle G, Pelikan J, Slonska Z, et al. Health literacy and public health: a systematic review and integration of definitions and models. BMC public health 2012;12(1):80.

4. Bilir N. Sağlık okur-yazarllğl/Health literacy. Turkish Journal of Public Health 2014;12(1):61-68.

5. Williams $M V$, Baker DW, Parker RM, Nurss JR. Relationship of functional health literacy to patients' knowledge of their chronic disease: A study of patients with hypertension and diabetes. Archives of Internal Medicine 1998;158(2):166.

6. Ad Hoc Committee on Health Literacy for the Council on Scientific Affairs, American Medical Association. Health Literacy: Report of the Council on Scientific Affairs. JAMA 1999;281(6):552-7.

7. Bohlman LN, Panzer AM, Kindig DA. Health Literacy: A Prescription to End Confusion. Washington, D.C.: National Academies Press 2004 [Erişim: 10.09.2019]. Web: http://www. nap.edu/catalog/10883

8. Nutbeam D. Helth promotion glossary. Health Promotion International 1998;13(4):349-64.

9. Nutbeam D. Health literacy as a public health goal: a challenge for contemporary health education and communication strategies into the 21st century. Health Promotion International 2000;15(3):259-67.

10. Deniz S, Öztaș D, Akbaba M. Birinci basamak sağlık hizmetlerinde çalışan sağlık personelinin sağlık okuryazarlığı düzeyinin ve etkileyen faktörlerin belirlenmesi. Sakarya Tip Dergisi 2018;8(2):214-28.

11. Özdoğan SB. Radyoterapi Alan Hasta ve Yakınlarının Sağlık Okuryazarllğı ve Gereksinimlerine Yönelik Öğretim Materyali Geliștirilmesi [Yüksek Lisans Tezi]. [Ankara]: Başkent Üniversitesi; 2014.

12. Sezer A. Sağlık Okuryazarlı̆̆ının Sağlıklı Yaşam Biçimi Davranışları İle İlişkisi [Doktora Tezi]. [İstanbul]: Marmara Üniversitesi; 2012 [Erşsim: 15.9.2019]. Web: https://tez.yok.gov. tr/UlusalTezMerkezi/TezGoster?key=7d53ed97e31a8bd307a257b743fb32ff70180749b5da3044684d473b2ec4f7d489c5103d590b5dfe

13. Tanriöver MD, Yıldırım HH, Demiray Ready N, Çakır B, Akalın E. Türkiye Sağlık Okuryazarlı̆̆ Araștırması. 1st ed. Ankara: Sağllk-Sen; 2014. 96 p.

14. Uğurlu Z, Akgün HS. Sağlık kurumlarına başvuran hastaların sağlık okuryazarllğının ve kullanılan eğitim materyallerinin să̆lk okuryazarlı̆̆ıa uygunluğunun değerlendirilmesi. Mersin Üniversitesi Sağlık Bilimleri Dergisi 2019;12(1):96-106.

15. Batterham RW, Hawkins M, Collins PA, Buchbinder R, Osborne RH. Health literacy: applying current concepts to improve health services and reduce health inequalities. Public Health 2016;132:3-12.

16. Sorensen K, Pelikan JM, Röthlin F, Ganahl K, Slonska Z, Doyle G, et al. Health literacy in Europe: comparative results of the European health literacy survey (HLS-EU). Eur J Public Health 2015;25(6):1053-8.

17. Kobayashi LC, Wardle J, Wolf MS, von Wagner C. Aging and Functional Health Literacy: A Systematic Review and Meta-Analysis. J Gerontol B Psychol Sci Soc Sci 2016;71(3):445-57.
18. Dennis S, Williams A, Taggart J, Newall A, Denney-Wilson E, Zwar N, et al. Which providers can bridge the health literacy gap in lifestyle risk factor modification education: a systematic review and narrative synthesis. BMC Fam Pract 2012;13(1):44.

19. Yilmazel G, Cetinkaya F. Health literacy among schoolteachers in Çorum, Turkey. East Mediterr Health J 2015;21(8):598-605.

20. Almaleh R, Helmy Y, Farhat E, Hasan H, Abdelhafez A. Assessment of health literacy among outpatient clinics attendees at Ain Shams University Hospitals, Egypt: a cross-sectional study. Public Health 2017;151:137-45.

21. Ozdemir H, Alper Z, Uncu Y, Bilgel N. Health literacy among adults: a study from Turkey. Health Education Research 2010;25(3):464-77.

22. Wagner $C v$., Knight $K$, Steptoe A, Wardle J. Functional health literacy and health-promoting behaviour in a national sample of British adults. Journal of Epidemiology \& Community Health 2007;61(12):1086-90.

23. Duong TV, Chang PW, Yang S-H, Chen $M-C$, Chao W-T, Chen T, et al. A New Comprehensive Short-form Health Literacy Survey Tool for Patients in General. Asian Nursing Research 2017;11(1):30-5.

24. Kutner M, Greenburg E, Jin Y, Paulsen C. The Health Literacy of America's Adults: Results from the 2003 National Assessment of Adult Literacy. NCES 2006-483. National Center for Education Statistics. 2006 [Erișim: 10.08.2019]; Web: http://eric.ed.gov/?id=ED493284

25. HLS-EU CONSORTIUM (2012). Comparative Report on Health Literacy In Eight EU Member States. The European Health Literacy Survey HLS-EU. 2012.

26. Tokuda Y, Doba N, Butler JP, Paasche-Orlow MK. Health literacy and physical and psychological wellbeing in Japanese adults. Patient Education and Counseling 2009;75(3):411-7.

27. Liu Y-B, Liu L, Li Y-F, Chen Y-L. Relationship between Health Literacy, Health-Related Behaviors and Health Status: A Survey of Elderly Chinese. IJERPH 2015;12(8):9714-25.

28. Inoue M, Takahashi M, Kai I. Impact of communicative and critical health literacy on understanding of diabetes care and self-efficacy in diabetes management: a cross-sectional study of primary care in Japan. BMC Fam Pract 2013;14(1):40.

29. Berens $E-M$, Vogt D, Messer M, Hurrelmann $K$, Schaeffer D. Health literacy among different age groups in Germany: results of a cross-sectional survey. BMC Public Health 2016;16(1):1151.

30. Doyle G, Cafferkey K, Fullam J. The European health literacy survey: Results from Ireland. Dublin: University College; 2012 [Erişim:05.08.2019]. Web: http://vc-health.kums.ac.ir/ kums_content/media/image/2013/09/33757_orig.pdf

31. Wolf MS, Gazmararian JA, Baker DW. Health Literacy and Functional Health Status Among Older Adults. Arch Intern Med 2005;165(17):1946-52.

32. Shah LC, West P, Bremmeyr K, Savoy-Moore RT. Health Literacy Instrument in Family Medicine: The 'Newest Vital Sign' Ease of Use and Correlates. J Am Board Fam Med 2010;23(2):195-203.

33. Jayasinghe UW, Harris MF, Parker SM, Litt J, van Driel M, Mazza D, et al. The impact of health literacy and life style risk factors on health-related quality of life of Australian patients. Health and Quality of Life Outcomes 2016;14(1):68.

34. Özaydın Ü, Can MF, Yllmaz S. Bireylerde Bazı Să̆lık Okuryazarlı̆̆ı Tutum ve Davranışları: Hatay İli Örneği. Smyrna Tip Dergisi 2018;(1):34-41. 